\title{
A Chitinase from Tex6 Maize Kernels Inhibits Growth of Aspergillus flavus
}

\author{
Kenneth G. Moore, Michael S. Price, Rebecca S. Boston, Arthur K. Weissinger, and Gary A. Payne
}

First author: Waters Corporation, 100 Cummings Center Suite 407N Beverly, MA 01915; second and fifth authors: Department of Plant Pathology, North Carolina State University; third author: Department of Botany, North Carolina State University; and fourth author: Department of Crop Science, North Carolina State University, Raleigh 27695. Accepted for publication 14 August 2003.

\begin{abstract}
Moore, K. G., Price, M. S., Boston, R. S., Weissinger, A. K., and Payne, G. A. 2004. A chitinase from Tex6 maize kernels inhibits growth of Aspergillus flavus. Phytopathology 94:82-87.

The maize inbred Tex6 has resistance to colonization and aflatoxin accumulation by Aspergillus flavus. A protein inhibitory to growth of $A$. flavus has been identified from aqueous extracts of mature Tex6 seeds. This study reports the purification of a chitinase associated with this inhibitory activity to electrophoretic homogeneity and the further characterization of its properties. The inhibitory protein, which has an $M_{\mathrm{r}}$ of

29,000 , as determined by sodium dodecyl sulfate-polyacrylamide gel electrophoresis, is an endochitinase that is also capable of exochitinase activity. The enzyme has an optimal $\mathrm{pH}$ of 5.5 and a temperature optimum of $45^{\circ} \mathrm{C}$. Chitinase activity in maize kernels peaked approximately 36 days after pollination. The Tex6 chitinase purified in this study is capable of inhibiting the growth of A. flavus by $50 \%$ at a concentration of $20 \mu \mathrm{g} / \mathrm{ml}$. Our data indicate that chitinase activity in Tex6 kernels makes a major contribution to the antifungal activity in this maize genotype. Partial peptide sequence of the chitinase showed it to differ from previously reported chitinases.
\end{abstract}

The fungus Aspergillus flavus is responsible for both pre- and postharvest accumulation of aflatoxin in maize (Zea mays) $(6,27)$. Concern about aflatoxin contamination is due to its potent carcinogenicity $(5,8,27,32)$; aflatoxin $\mathrm{B}_{1}$ is the most potent naturally occurring carcinogen known (32). It can induce liver tumors in rats at concentrations as low as $1 \times 10^{-9}$ percent of the rat diet (36). Because of health concerns associated with aflatoxin contamination, the Food and Drug Administration regulates the concentration of aflatoxin allowed in feed and foods marketed within the United States. Internationally, other countries set their own limits for allowable aflatoxin contamination; often these levels are lower than acceptable by the United States. Aflatoxin contamination is clearly a hazard to animal health and an impediment to trade (24).

Aflatoxin contamination of maize in the United States is associated with above average temperature and below average rainfall $(27,33)$. Cultural practices are effective in reducing aflatoxin contamination $(4,27,33)$, but no currently available practice can prevent aflatoxin contamination in years favorable for the growth of the fungus. Plant resistance has proven successful for other diseases of maize and there is promise that this will be the case for reducing contamination of maize with aflatoxin. Breeding programs to identify and incorporate resistance to aflatoxin accumulation are ongoing, and a number of genotypes have been identified with resistance $(2-5,7,13,30,34,35,38)$. Unfortunately, the incorporation of high resistance to either infection or aflatoxin accumulation in commercially valuable hybrids has not been successful.

Certainly the ability to identify markers associated with resistance would greatly facilitate the incorporation of resistance into desirable genotypes. To this end, research has focused on identifying compounds in maize seeds that inhibit fungal growth or the

Corresponding author: G. A. Payne; E-mail address: gary_payne@ncsu.edu

Publication no. P-2003-1031-01R

(C) 2004 The American Phytopathological Society accumulation of aflatoxin. The goal of this research is to identify markers that can be used to follow the segregation of resistance in a breeding population. Several compounds from seeds have been associated with resistance to infection by A. flavus. These include seed waxes $(12,28)$, an $\alpha$-amylase inhibitor $(9)$, a trypsin inhibitor (6), ribosome inactivating proteins $(11,25)$, zeamatin (11), and a $\beta$-1,3-glucanase (21). Proteins with chitinase activity have been shown to accumulate in maize seeds in response to infection by $A$. flavus, but a definitive role for these compounds in host resistance has not been determined $(18,37)$.

Because maize inbred Tex6 has been shown to have resistance to infection and aflatoxin accumulation by $A$. flavus $(4,5,13)$, we reasoned that this genotype would be a good candidate for studies directed at identifying compounds inhibitory to A. flavus and aflatoxin accumulation. We recently reported the isolation of two inhibitory compounds from Tex6; one that inhibits fungal growth and the other that inhibits aflatoxin formation (14). In this paper, we report further characterization of the compound shown to inhibit fungal growth and show that it is a chitinase that differs from previously reported chitinases.

\section{MATERIALS AND METHODS}

Tex6 extract preparation. Seed of Tex6, an inbred selfed from southern corn cv. Whitemaster (PI 401763) (5), was supplied by D. White at the University of Illinois at Urbana. Tex6 was grown and self-pollinated at the North Carolina Central Crops Research Station, Clayton, in the summers of 1998 and 1999. Ears were harvested at the developmental times indicated (between 26 and 40 days after pollination) and rapidly frozen in liquid nitrogen. The kernels were shelled onto dry ice and stored at $-80^{\circ} \mathrm{C}$ until use. Seeds were ground at $4^{\circ} \mathrm{C}$ in a coffee grinder. The powder was suspended in $50 \mathrm{mM}$ citrate buffer, $\mathrm{pH} 5.5$, and stirred for $1 \mathrm{~h}$ ( $1 \mathrm{~kg}$ of powder to 3 liters of citrate buffer). This slurry was then filtered through cheesecloth and centrifuged at $6,000 \times g$ for $30 \mathrm{~min}$. The resulting supernatant was filtered through Miracloth and designated Tex6 extract. 
Fungal inhibition bioassay. A. flavus strain 656-2 GAP 13-22 (14) was used in all bioassays. Inhibition of A. flavus by Tex6 was monitored according to an assay adapted from Huang et al. (14). Briefly, $10^{6}$ conidia were incubated in 24-well microtiter plates in peptone mineral salts medium containing the sample to be tested $(1,050 \mu \mathrm{l}$ total volume per well). The plates were incubated at $28^{\circ} \mathrm{C}$ for $\approx 90 \mathrm{~h}$. The mycelial pads were harvested, washed with double-distilled $\mathrm{H}_{2} \mathrm{O}$ (to remove salts and growth medium), dried, and weighed. Quantification of fungal inhibition was expressed relative to buffer controls.

Chitinase assays. $N$-acetylglucosamine, $N, N^{\prime}$-diacetylchitobiose, and $N, N^{\prime}, N^{\prime \prime}$-triacetylchitotriose were obtained from Sigma Chemical, St. Louis. Chitinase activity was measured using highperformance liquid chromatography (HPLC) to quantify the concentration of chitin breakdown products. These breakdown products ( $N$-acetylglucosamines) were separated on a carbohydrate analysis column (Waters Corp., Milford, MA) using a mobile phase of $75: 25$ acetonitrile/ $\mathrm{H}_{2} \mathrm{O}$ at a flow rate of $0.9 \mathrm{ml} / \mathrm{min}$. Detection was determined at $210 \mathrm{~nm}$. The retention times of monomer $\mathrm{N}$-acetylglucosamine, dimer $\mathrm{N}$-acetylglucosamine $\left(N, N^{\prime}\right.$ diacetylchitobiose), and trimer $N$-acetylglucosamine $\left(N, N^{\prime}, N^{\prime \prime}\right.$-triacetylchitotriose) were 4.5, 8.0, and $14.2 \mathrm{~min}$, respectively.

The chitinase activity assay was conducted by incubating colloidal chitin and Tex6 extract or column fractions in $50 \mathrm{mM}$ citrate, $\mathrm{pH} 5.5$, at $28^{\circ} \mathrm{C}$. At selected time points, an aliquot was removed from the reaction vessel and injected directly onto the HPLC column. Integration of peak area associated with standard curves for the concentrations of mono, di, and tri $\mathrm{N}$-acetylglucosamines gave a direct reading of chitinase activity. The temperature study was done at $\mathrm{pH} 5.5$, and the $\mathrm{pH}$ study was done at $28^{\circ} \mathrm{C}$.

Purification of Tex6 chitinase. All steps were performed at $4^{\circ} \mathrm{C}$ unless otherwise noted. Extracts from mature seed (described previously) were applied to a Sephadex G-100 GFC column $(15 \mathrm{~cm}$ by $1.5 \mathrm{~m}$ ) and eluted at a flow rate of $9 \mathrm{ml} / \mathrm{h}$. The fractions that displayed antifungal activity were pooled and concentrated with a centriprep-10 unit (Millipore, Billerica, MA), and the pooled sample was subjected to chitin affinity chromatography. The affinity column $(0.5$ by $10 \mathrm{~cm})$ contained $5 \mathrm{~g}$ of purified powder chitin from crab shells (Sigma Chemical) suspended in $50 \mathrm{mM}$ citrate, $\mathrm{pH}$ 5.5. The column was washed with $50 \mathrm{mM}$ citrate, $\mathrm{pH}$ 5.5 , and eluted with $2 \mathrm{M} \mathrm{NaCl}$ by gravity flow. Active fractions from the affinity column were then added to a carboxy-methyl (CM) column (Bio-Rad Laboratories, Hercules, CA), washed with $50 \mathrm{mM}$ citrate ( $\mathrm{pH} 5.5)$, and eluted sequentially with $75 \mathrm{mM} \mathrm{NaCl}$ and $125 \mathrm{mM} \mathrm{NaCl}$. sodium dodecyl sulfate-polyacrylamide gel electrophoresis (SDS-PAGE) was conducted as described previously (19). Gels were stained and visualized with Coomassie brilliant blue G-250.

\section{RESULTS}

Fractionation of the antifungal compound in Tex6 maize seeds. Previous research from our lab demonstrated that the fungal resistance of Tex6 maize is protein-mediated (14). This project sought to identify the protein or proteins responsible for the antifungal activity. We passed Tex6 seed extract through a Sephadex G-100 GFC column and assayed the resulting fractions for fungal inhibition as described previously. Figure 1A shows the results of the bioassay superimposed on the protein elution profile from the G-100 column. The growth of A. flavus was relatively unaffected by fractions from the G-100 column until fractions from the 25,000 to $35,000 M_{\mathrm{r}}$ region were assayed (elution volume 600 to $800 \mathrm{ml}$ ). At this point, there was a dramatic decrease in fungal growth, which signifies the presence of inhibitory compounds. The antifungal activity coincided with a small but distinct peak of protein.

Among the previous reports of antifungal plant proteins with molecular weights of 25 to $35 \mathrm{kDa}$ are $\beta$-1,3-glucanases $(17,23)$ and chitinases $(1,5,10)$. We tested Tex6 extract for chitinase ac- tivity on a chitin agar plate and observed a small zone of clearing after 3 days incubation. Thus, the Tex6 extract contained an activity capable of degrading chitin (data not shown).

Evidence of both a chitin-degrading activity in the crude extract and an antifungal activity of $\approx 30 \mathrm{kDa}$ suggested that the antifungal activity in Tex6 kernels might be a chitinase. Fractions from the G-100 column were assayed for chitinase activity by the chitin activity assay as described previously. Figure $1 \mathrm{~B}$ shows a single large peak of chitinase activity with two shoulders. The chitinase activity was maximal in the fractions having the largest inhibitory effect on fungal growth. This circumstantial link between chitinase activity and antifungal activity prompted us to investigate whether the antifungal activity was due to a chitinase. Fractions from the G-100 column showing antifungal activity were pooled, concentrated, and applied to a chitin affinity column. The column was washed with $50 \mathrm{mM}$ citrate and eluted with $2 \mathrm{M} \mathrm{NaCl}$. Three fractions were then investigated: fraction 1, the active G-100 column fractions that had been shown to be antifungal; fraction 2, the material that was washed from the chitin affinity column with $50 \mathrm{mM}$ citrate (a fraction in which the chitinase activity had presumably been removed); and fraction 3 , the material eluted from the chitin affinity column with $2 \mathrm{M} \mathrm{NaCl}$ (a fraction which should contain chitinase activity). The $2 \mathrm{M} \mathrm{NaCl}$ eluant from the chitin affinity column was dialyzed 4,000:1 into $50 \mathrm{mM}$ citrate, $\mathrm{pH}$ 5.5. The pooled antifungal fractions from the G-100 column
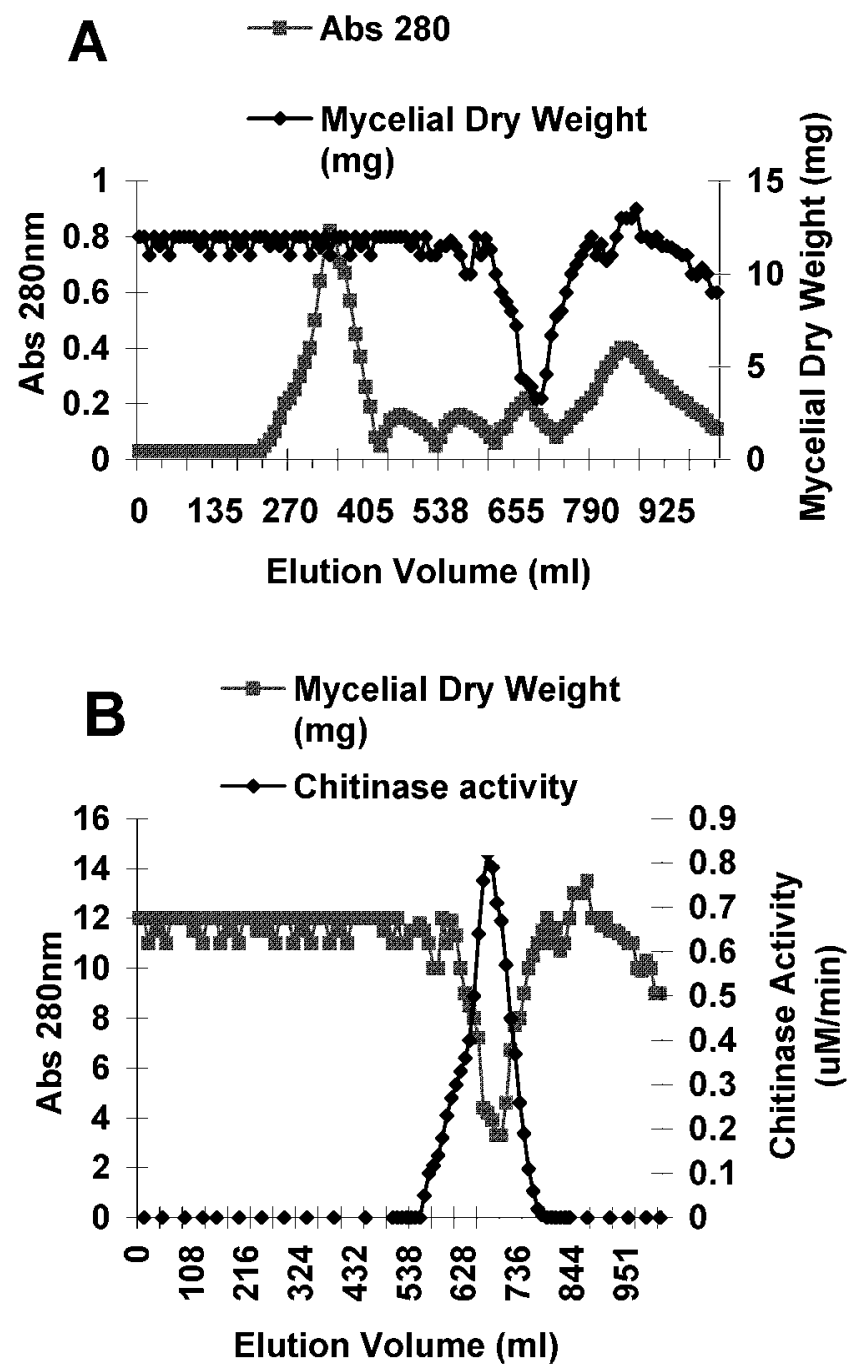

Fig. 1. Gel filtration chromatography of Tex6 seed extracts. Tex6 seed extracts were applied to a Sephadex G-100 column and the fractions were assayed for A, protein and inhibitory activity against Aspergillus flavus and B, chitinase activity and inhibitory activity against $A$. flavus. 
were compared with the citrate wash and the $\mathrm{NaCl}$ wash from the chitin affinity column for chitinase activity, as determined by HPLC, and for fungal growth inhibition.

In the absence of seed extracts (control), A. flavus grew to a dry weight of $13.2 \mathrm{mg}$ (Fig. 2A). In contrast, A. flavus growth was reduced to $0.1 \mathrm{mg}$ when it was cultured on the pooled active fractions from the G-100 column that were applied to the chitin affinity column (fraction 1). The chitinase activity in fraction 1 was $1.3 \mu \mathrm{g} / \mathrm{min} / \mathrm{mg}$ of protein. The citrate wash from the chitin affinity column (fraction 2), which had the majority of the chitinase activity removed (remaining chitinase activity was $0.1 \mu \mathrm{g} / \mathrm{min} / \mathrm{mg}$ ), supported fungal growth to $7.7 \mathrm{mg}$. This fraction retained $58 \%$ of its antifungal properties. Finally, the $2 \mathrm{M} \mathrm{NaCl}$ wash from the chitinase affinity column (Fraction 3 ) that contained a chitinase activity of $2,000 \mu \mathrm{g} / \mathrm{min} / \mathrm{mg}$ reduced fungal growth to $0.3 \mathrm{mg}$ of

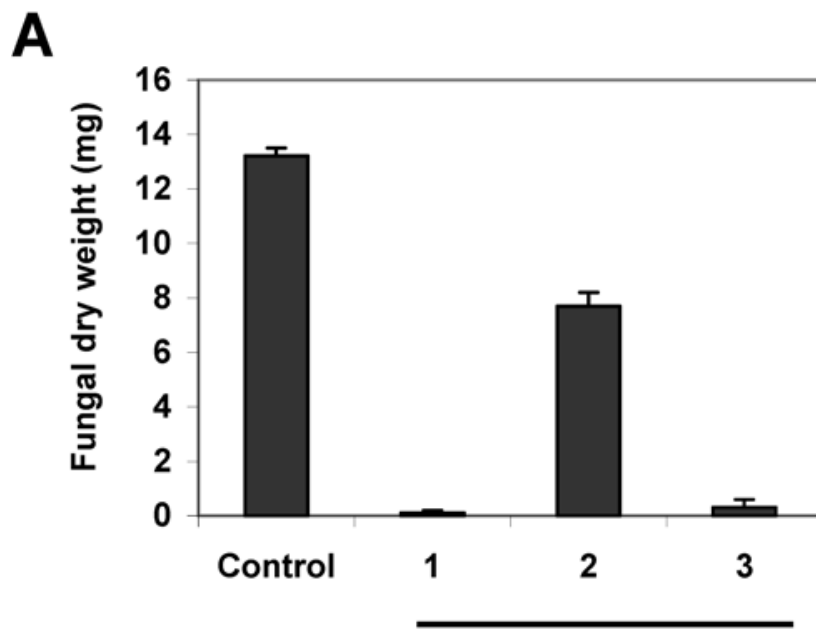

Fractions

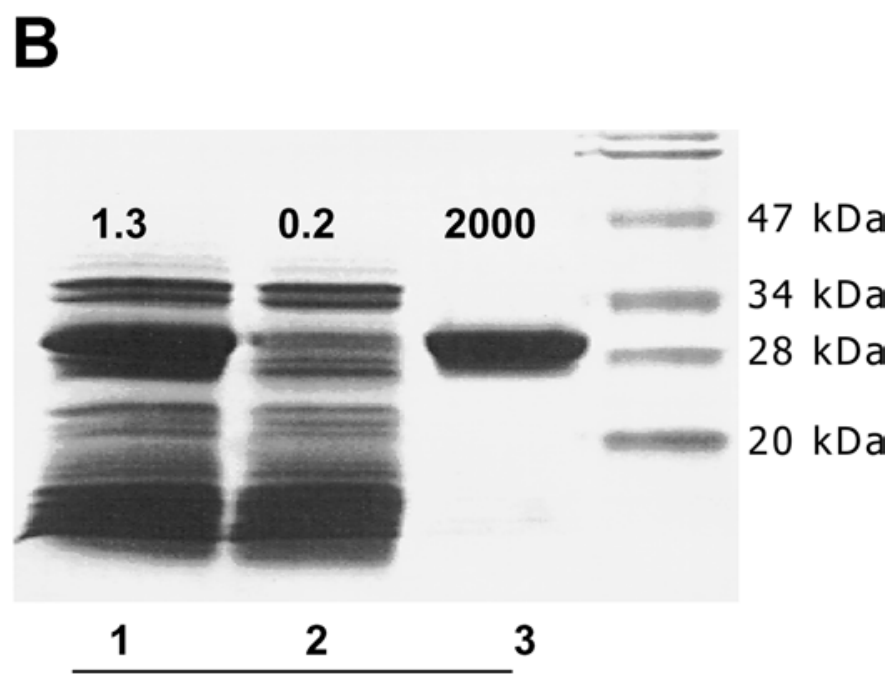

Fractions

Fig. 2. Analysis of Tex6 seed proteins after fractionation on a chitin affinity column. A, Growth of Aspergillus flavus in the absence of Tex6 seed proteins (control) and in the presence of three fractions subjected to chitin affinity chromatography. Fraction 1 is the pooled active fractions from the G-100 column described in Figure 1 that were applied to the chitin affinity column. High-performance liquid chromatography analysis showed chitinase activity to be $1.3 \mu \mathrm{g} / \mathrm{min} / \mathrm{mg}$. Fraction 2 is the wash from the chitin affinity column (chitinase activity was $0.1 \mu \mathrm{g} / \mathrm{min} / \mathrm{mg}$ ). Fraction 3 is the $2 \mathrm{M} \mathrm{NaCl}$ eluant from the chitin affinity column (chitinase activity was $2,000 \mu \mathrm{g} / \mathrm{min} / \mathrm{mg}$ ). In the growth assay, $700 \mu \mathrm{l}$ of each fraction was assayed for antifungal activity according to the antifungal assay described in the text. B, A sodium dodecyl sulfate-polyacrylamide gel electrophoresis chromatogram of protein preparations subjected to chitin affinity chromatography. Lane 4 is a molecular size marker. fungal dry weight. This fraction from the chitin affinity column reduced fungal growth by $98 \%$ and retained greater than $76 \%$ of the chitinase activity of fraction 1.

SDS-PAGE was used to visualize the partitioning of protein by the chitin affinity column (Fig. 2B). Coomassie blue staining of the gel showed a prominent band $\left(M_{\mathrm{r}} \approx 29,000\right)$ in the fraction eluted from the chitin affinity column with $2 \mathrm{M} \mathrm{NaCl}$ (fraction 3). This gel also showed that the majority of this putative chitinase band at $29 \mathrm{kDa}$ had been removed from the G-100 fractions by the chitin affinity column, thus confirming the data obtained from HPLC analysis.

Purification of Tex6 chitinase. Chitinase activity has been reported in both developing and mature kernels as well as in germinating seeds of maize. We assayed Tex6 kernels for chitinase activity in immature seed between 26 and 40 days after pollination. The chitinase activity reached maximal levels approximately 36 days after pollination (Table 1). Therefore, we used 36-day postpollination kernels for subsequent chitinase purification. The chitin affinity column removed the majority of contaminating proteins leaving a single band at $M_{\mathrm{r}} \approx 29,000$ in a SDS-PAGE gel. Upon close inspection of the SDS-PAGE gel, two bands of $M_{\mathrm{r}} \approx$ 29,000 were present (Fig. 3B, lane 3). The chitinase fractions

TABLE 1. Chitinase activity in Tex6 kernels at selected days after pollination

\begin{tabular}{lc}
\hline Days after pollination & Chitinase activity $(\mu \mathrm{M} / \mathrm{min} / \mathrm{mg})$ \\
\hline 10 & $10.1 \pm 0.2$ \\
28 & $11.1 \pm 0.4$ \\
30 & $12.0 \pm 0.5$ \\
33 & $13.3 \pm 0.6$ \\
36 & $14.5 \pm 0.3$ \\
39 & $13.5 \pm 0.4$ \\
40 & $12.0 \pm 0.8$ \\
\hline
\end{tabular}
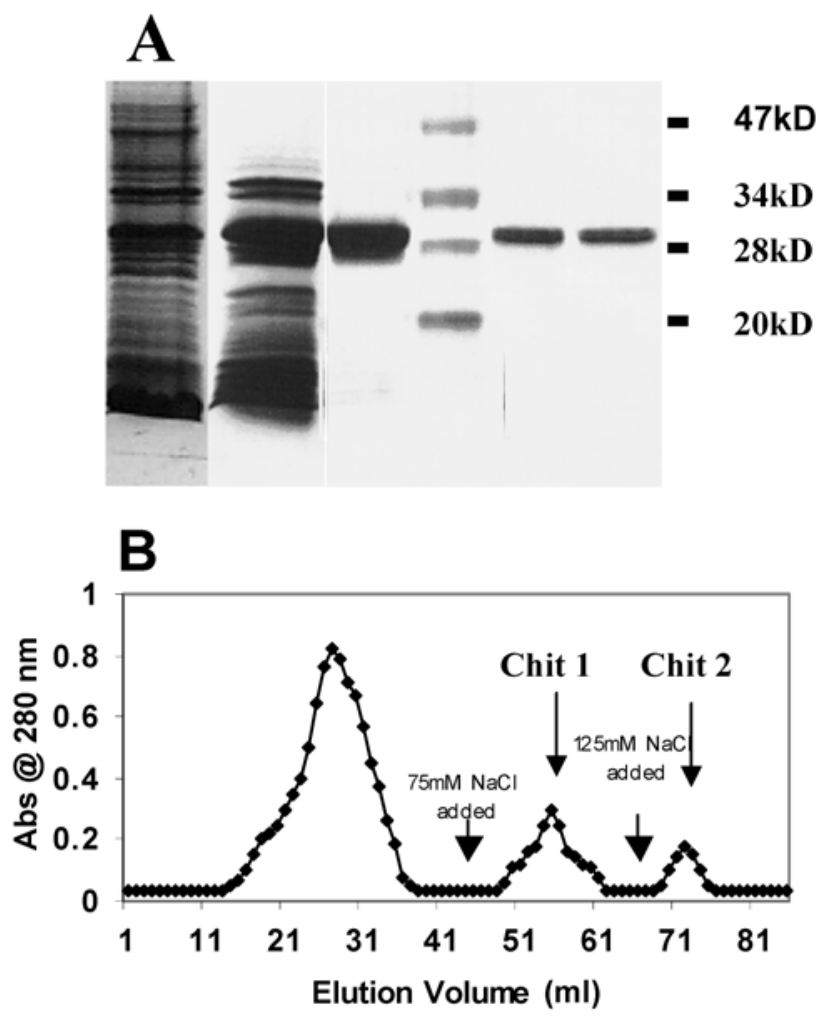

Fig. 3. Separation of two putative chitinases from Tex6 by gel chromatography and sodium dodecyl sulfate-polyacrylamide gel electrophoresis (SDS-PAGE). A, SDS-PAGE chromatography of the Tex6 protein fractions showing inhibitory activity. Lane 1, Tex6 seed extract; lane 2, active fractions from the G-100 column; lane 3, active fractions from the chitin affinity column; lane 4, molecular weight standards; lane 5, chitinase 1 ; and lane 6 , chitinase 2 . B, Elution of chitinase 1 and 2 from a carboxy-methyl (CM) column. 
from the affinity column were then added to a Bio-Rad CM column washed sequentially with $75 \mathrm{mM} \mathrm{NaCl}$ and $125 \mathrm{mM}$ $\mathrm{NaCl}$. The chitinase that was released from the $\mathrm{CM}$ column with $75 \mathrm{mM} \mathrm{NaCl}$ was, by far, the more abundant of the two chitinases. This protein migrated as a single band through SDS-polyacrylamide gels and represented a 190-fold purification based on specific activity (Table 2). In immunoblots, it showed cross-reaction with antibodies derived against cucumber chitinase (data not shown). We will refer to this protein as chitinase 1 . The chitinase released with the $125 \mathrm{mM} \mathrm{NaCl}$ wash migrated as a single band that represented a small portion of the total chitinase activity. Due to the small yield of the second chitinase, no further evaluations of its properties were possible.

Characterization of chitinase 1. The purified protein had an $M_{\mathrm{r}}$ of 29,000 as determined by SDS-PAGE. Its optimum $\mathrm{pH}$ was 5.5 with activity dropping off sharply after pH 6.0 (Fig. 4A). Its

TABLE 2. Purification of Tex6 chitinase 1 from maize kernels ${ }^{a}$

\begin{tabular}{lrccrr}
\hline & $\begin{array}{c}\text { Total } \\
\text { protein } \\
(\mathrm{mg})\end{array}$ & $\begin{array}{c}\text { Total } \\
\text { activity } \\
(\mu \mathrm{M} / \mathrm{min})\end{array}$ & $\begin{array}{c}\text { Specific } \\
\text { activity } \\
(\mu \mathrm{M} / \mathrm{min} / \mathrm{mg})\end{array}$ & $\begin{array}{c}\text { Fold } \\
\text { purification }\end{array}$ & $\begin{array}{c}\% \\
\text { Yield }\end{array}$ \\
\hline Tex6 extract & 4,200 & 58,000 & 14 & 1 & 100 \\
G-100 & 290 & 34,000 & 140 & 10 & 70 \\
Affinity & 9 & 22,000 & 2,500 & 180 & 40 \\
CM & 3 & 7,800 & 2,600 & 190 & 14 \\
\hline
\end{tabular}

a The chitinase was purified to electrophoretic homogeneity, as determined by sodium dodecyl sulfate-polyacrylamide gel electrophoresis, resulting in a 190-fold enrichment as determined by specific activity.
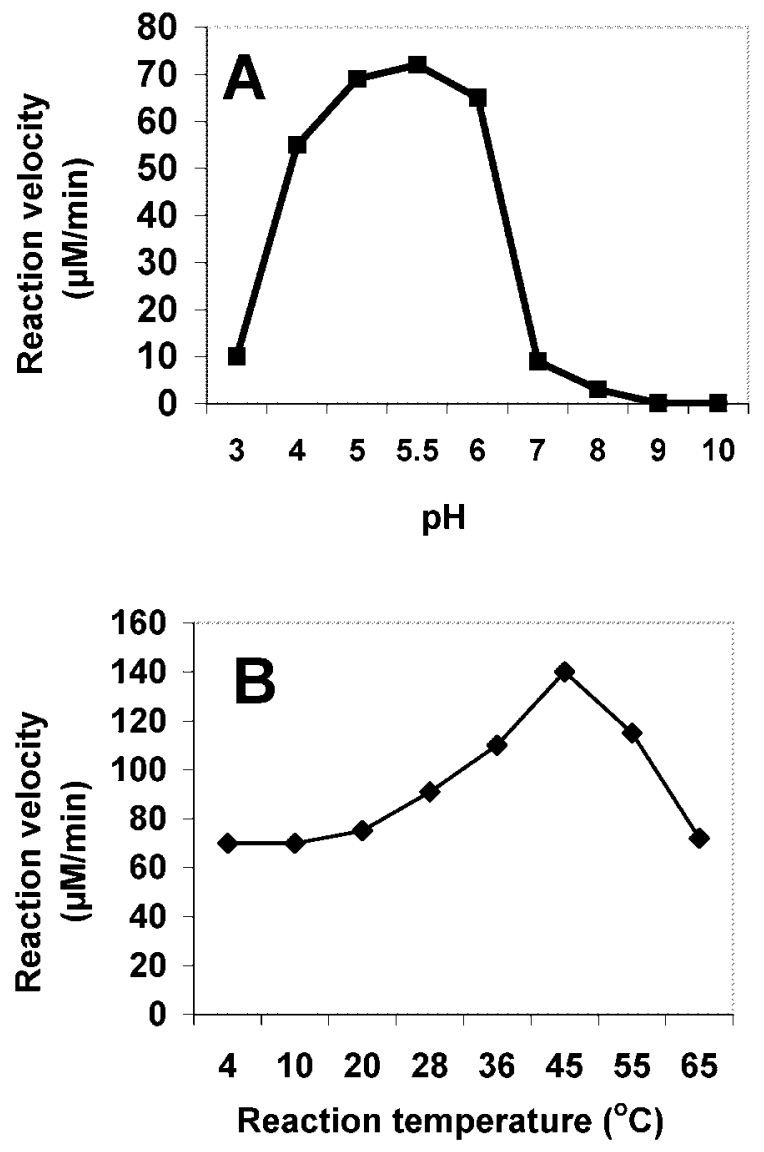

Fig. 4. The effect of $\mathrm{pH}$ and temperature on Tex6 chitinase 1 activity. Initial reaction velocities were used to determine the rate of reaction. The appearance of chitin breakdown products (mono and di $N$-acetylglucosamines) was monitored by high-performance liquid chromatography analysis. A, Reaction velocities of Tex6 chitinase 1 at $\mathrm{pH}$ values ranging from 3 to 10 . B, Reaction velocities of Tex6 chitinase 1 at temperatures from 4 to $65^{\circ} \mathrm{C}$. optimum temperature was $45^{\circ} \mathrm{C}$ (Fig. 4B). It is interesting to note that $50 \%$ of the maximal rate of enzymatic activity was still observed at $4^{\circ} \mathrm{C}$.

HPLC has proven to be a powerful tool because it permits the monitoring of the appearance of chitin breakdown products $(7,26)$. HPLC fractionation showed that the initial product of the reaction of Tex6 chitinase 1 was the dimer of $\mathrm{N}$-acetylglucosamine $\left(N, N^{\prime}-\right.$ diacetylchitobiose). Only as the concentration of dimer began to rise did we see the appearance of monomers of $N$-acetylglucosamine (Fig. 5). Late in the reaction, we also were able to detect trimers of $\mathrm{N}$-acetylglucosamine as well as low concentrations of higher order oligomers of $\mathrm{N}$-acetylglucosamines. These data suggest that Tex6 chitinase 1 is primarily an endochitinase although it is also capable of exochitinase activity.

Antifungal characterization of Tex6 chitinase 1. A dosage response curve was conducted using the purified Tex6 chitinase 1 to determine its antifungal characteristics against A. flavus. Mycelial dry weight was determined after the fungus was grown in the presence of chitinase 1 at concentrations from 5 to $2,000 \mu \mathrm{g} / \mathrm{ml}$. These data showed that $50 \%$ growth inhibition of A. flavus was achieved at a protein concentration of $20 \mu \mathrm{g} / \mathrm{ml}$ (Fig. 6). Fungal growth was not detected at a protein concentration of $2,000 \mu \mathrm{g} / \mathrm{ml}$.

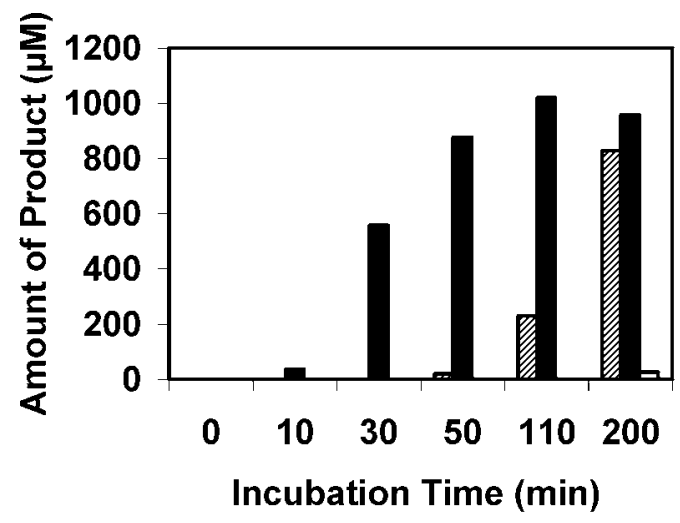

Fig. 5. Release of chitin polymers after incubation of chitin at $28^{\circ} \mathrm{C}$ with $20 \mu \mathrm{l}$ of Tex6 chitinase 1 at a concentration of $5 \mathrm{mg} / \mathrm{ml}$. The initial product of the reaction is solely the dimer of $N$-acetylglucosamine ( $N, N^{\prime}$-diacetylchitobiose). As the concentration of dimer increases, the monomer of $\mathrm{N}$ acetylglucosamine appears. Late in the reaction, trimer and higher order oligomers of $\mathrm{N}$-acetylglucosamine appear.

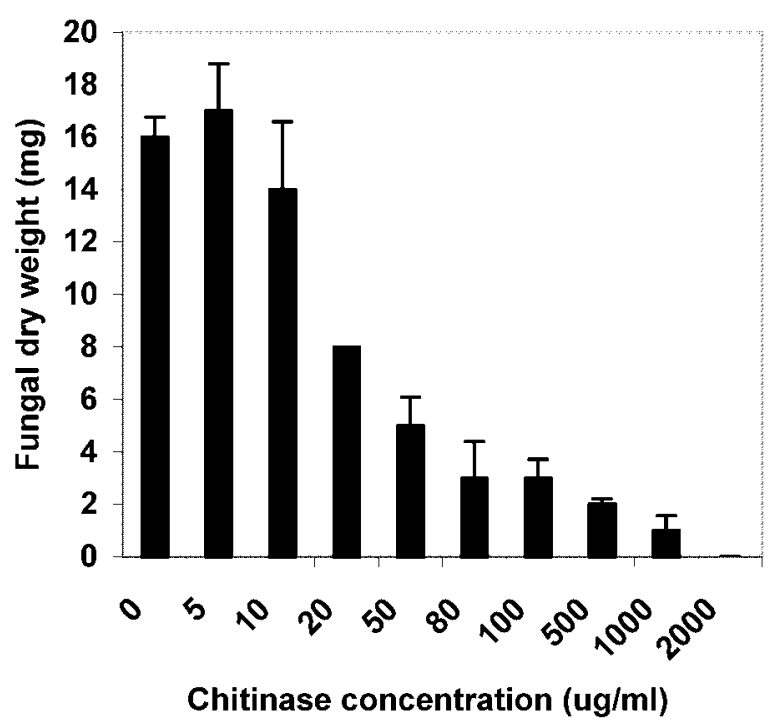

Fig. 6. Growth of Aspergillus flavus in the presence of differing concentrations of Tex 6 chitinase 1 . The fungus was cultured at $28^{\circ} \mathrm{C}$ in differing concentrations of chitinase for $90 \mathrm{~h}$. 
Sequence analysis of Tex6 chitinase. Initial attempts at Namino terminal sequencing suggested that the protein was $\mathrm{N}$ blocked at the amino terminus. We were able to obtain internal amino acid sequence data from three regions of the protein. Figure 7 shows the amino acid sequence and the alignment of the Tex6 chitinase 1 compared with the maize seed chitinases A and B reported by Huynh et al. (15). Region one of Tex6 chitinase 1 showed $80 \%$ amino acid sequence identity to chitinase A and $93 \%$ sequence identity to chitinase B. Region two showed $91 \%$ sequence identity with both chitinases A and B. Region three of the Tex6 chitinase showed $91 \%$ sequence identity with chitinase A and $84 \%$ sequence identity with chitinase B (Fig. 7).

\section{DISCUSSION}

The focus of this study was to characterize the protein in Tex6 seed extracts that inhibits growth of A. flavus. A linkage was found between antifungal activity and chitinase activity in Tex6 kernels. When chitinase activity was removed from Tex6 seed extracts by a chitinase affinity column, the antifungal properties of the extract decreased dramatically. In contrast, fractions eluting from the affinity column with chitinase activity were inhibitory to fungal growth. Further, fungal inhibitory activity followed chitinase activity throughout the purification protocol, and at the final step of purification, it was associated with a single protein band found in an SDS gel. Partial peptide sequencing of the inhibitory protein showed sequence similarity to a known maize seed chitinase. These results indicate that chitinase activity is a primary component of the antifungal activity in Tex6 maize kernels.

The sequences of the peptides of the Tex 6 chitinase place this chitinase in the Chia4 gene family (20). It is most similar to chitinases $\mathrm{A}$ and $\mathrm{B}$, two maize chitinases that have been shown to have antifungal activity (15). However, it is not identical to either of these two chitinases, and we hypothesize that these differences are important for the enhanced antifungal activity of the Tex6 chitinase. Minor modifications in sequence can greatly affect the activity of chitinases. Chitinases A and B, for example, show $91 \%$ nucleotide sequence identity and $87 \%$ amino acid identity, but have marked differences in their inhibitory activity to fungi (15). Both of these chitinases inhibited the growth of Fusarium oxysporum, Alternaria solani, and Trichoderma reesei, but required 10 times more chitinase B than chitinase A to cause the same degree of inhibition. Neither of these chitinases inhibited the growth of the plant pathogens Gaeumannomyces graminis, Sclerotinia sclerotiorum, or Phytophthora infestans.

The chitinase from Tex6 appears to be in a different gene family than two other chitinases (pCh2 and pCh11) isolated from maize leaves (37). These chitinases are members of the Chial gene

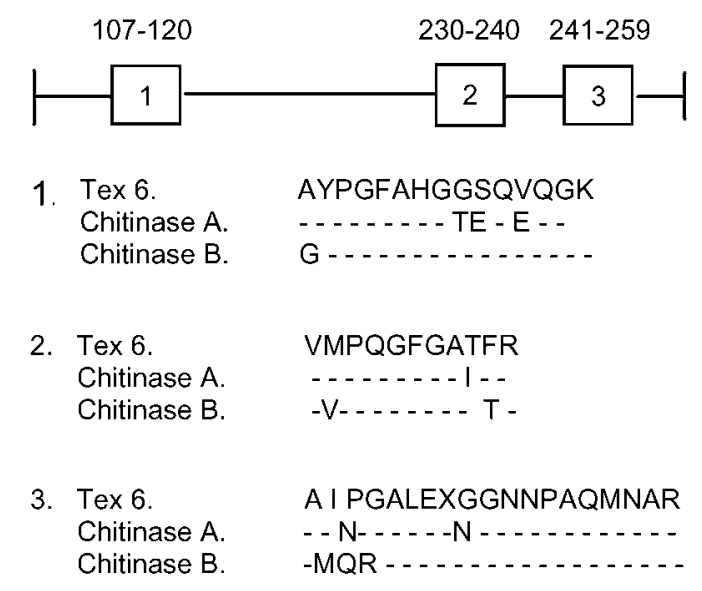

Fig. 7. Comparison of partial peptide sequence of Tex6 chitinase 1 with maize chitinases $\mathrm{A}$ and $\mathrm{B}$ (15). family (20). Both of these chitinases are present in maize kernels and were induced in damaged and A. flavus-inoculated kernels. The greatest induction of chitinase $\mathrm{pCh} 2$ and $\mathrm{pCh} 11$ transcripts was found in the aleurone layers of the seed. Transcript abundance was much greater for $\mathrm{pCh} 2$ than for pCh11. Only low levels of transcripts were found in the embryo and no transcripts were observed in the endosperm. Transcripts of pCh2 were also induced in maize calli cultured with A. flavus (37), but no evidence was found correlating chitinase activity in maize calli with inhibition of A. flavus (21).

Ji et al. (18) also reported a chitinase induced in maize seeds in response to infection by $A$. flavus. They found a $29-\mathrm{kDa}$ protein with chitinase activity that was induced in developing maize seeds by infection with $A$. flavus, but not after infection with $F$. verticillioides or drought stress. The biological activity of this chitinase against $A$. flavus was not tested.

Chitinase activity in Tex6 maize seeds appeared to increase as the seed matured up to 36 days after pollination. Interestingly, in a comparison between resistant and susceptible maize hybrids, Windham and Williams (34) found that the significant differences between resistant and susceptible hybrids were not detected until 42 days after midsilk, indicating that the factor(s) associated with kernel resistance increases with kernel maturity.

Although there are several reports in the literature of endochitinases from plants (10), we are unaware of any other chitinase that has been isolated from plants with inhibitory activity against A. flavus. The specificity of chitinases for fungal species has been reported $(15,17,31)$, but the mechanism of this specificity remains unknown. We evaluated the Tex6 chitinase for activity against $F$. verticillioides and found no inhibitory activity at $1,275 \mu \mathrm{g} / \mathrm{ml}$.

In contrast, the Tex6 chitinase shows efficacy against $A$. flavus at a concentration of $20 \mu \mathrm{g} / \mathrm{ml}$. Huynh et al. (15) tested maize seed chitinases using a plate-clearing assay and found efficacy by adding $10 \mu \mathrm{g}$ of purified protein in a volume of $10 \mu \mathrm{l}$. Our level of efficacy of $20 \mu \mathrm{g} / \mathrm{ml}$ equates to $0.2 \mu \mathrm{g}$ per $10 \mu \mathrm{l}$, suggesting that the Tex6 chitinase has greater inhibitory properties against $A$. flavus than chitinase $\mathrm{A}$ and chitinase $\mathrm{B}$ against the fungi tested. Thus, the Tex6 chitinase appears to have high activity against $A$. flavus as well as specificity for A. flavus.

While our data support a role of a chitinase in the resistance of Tex6 to A. flavus, other factors likely work in concert with the chitinase to confer the degree of resistance observed in the field. Several reports have implicated the synergism of two or more pathogenesis-related proteins in causing a dramatic increase in the effective lethality to a potential pathogen $(16,17,22,29,31)$. Mauch et al. (22) and Ji and Kuc (17) observed a synergistic effect through the combination of $\beta$-1,3-glucosidase and chitinase. Regardless, these compounds can serve as markers in breeding programs aimed at increasing the resistance of maize hybrids to aflatoxin contamination. Further, knowing the profile of inhibitory compounds present in different maize genotypes with resistance may allow the combination of different sources of resistance into a single genotype.

\section{ACKNOWLEDGMENTS}

This study was supported by the U.S. Department of Agriculture Cooperative Agreement 58-6435-1-113 for the elimination of aflatoxin contamination in food and feeds and by a grant from the Corn Growers Association of North Carolina. K. Moore was the recipient of a post doctoral fellowship funded by a Tri-Agency (DOE-NSF-USDA) grant administered by the National Science Foundation to the Interdisciplinary Research Training Group on Transgenic Plant Technology for Laboratory and Field Applications (BIR-9426089).

\section{LITERATURE CITED}

1. Azarkan, M., Amrani, A., Nijs, M., Vandermeers, A., Zerhouni, A., Smolders, N., and Looze, Y. 1997. Carica papaya latex is a rich source of a class II chitinase. Phytochem. Oxford 46:1319-1325. 
2. Brown, R. L., Chen, Z. Y., Cleveland, T. E., and Russin, J. S. 1999. Advances in the development of host resistance in corn to aflatoxin contamination by Aspergillus flavus. Phytopathology 89:113-117.

3. Brown, R. L., Cleveland, T. E., Payne, G. A., Woloshuk, C. P., Campbell, K. W., and White, D. G. 1995. Determination of resistance to aflatoxin production in maize kernels and detection of fungal colonization using an Aspergillus flavus transformant expressing Escherichia coli $\beta$ glucuronidase. Phytopathology 85:983-989.

4. Campbell, K. W., and White, D. G. 1995. Inheritance of resistance to Aspergillus ear rot and aflatoxin in corn genotypes. Phytopathology 85:886-896.

5. Campbell, K. W., and White, D. G. 1995. Evaluation of corn genotypes for resistance to Aspergillus ear rot, kernel infection, and aflatoxin production. Plant Dis. 79:1039-1045.

6. Chen, Z. Y., Brown, R. L., Russin, J. S., Lax, A. R., and Cleveland, T. E. 1999. A corn trypsin inhibitor with antifungal activity inhibits Aspergillus flavus alpha-amylase. Phytopathology 89:902-907.

7. Deane, E. E., Whipps, J. M., Lynch, J. M., and Peberdy, J. F. 1998. The purification and characterization of a Trichoderma harzianum exochitinase. Biochim. Biophys. Acta 1383:101-110.

8. Edds, G. T. 1973. Acute aflatoxicosis: A review. J. Am. Vet. Med. Assoc. 162:304-309.

9. Fakhoury, A. M., and Woloshuk, C. P. 2001. Inhibition of growth of Aspergillus flavus and fungal alpha-amylases by a lectin-like protein from Lablab purpureus. Mol. Plant-Microbe Interact. 14:955-961.

10. Graham, L. S., and Sticklen, M. B. 1994. Plant chitinases. Can. J. Bot. 72:1057-1083.

11. Guo, B. Z., Chen, Z. Y., Brown, R. L., Lax, A. R., Cleveland, T. E., Russian, J. S., Metha, A. D., Selitrennikoff, C. P., and Widstrom, N. W. 1997. Germination induces accumulation of specific proteins and antifungal activities in corn kernels. Phytopathology 87:1174-1178.

12. Guo, B. Z., Russin, J. S., Cleveland, T. E., Brown, R. L., and Widstrom, N. W. 1995. Wax and cutin layers in maize kernels associated with resistance to aflatoxin production by Aspergillus flavus. J. Food Prot. 58:296-300.

13. Hamblin, A. M., and White, D. G. 2000. Inheritance of resistance to Aspergillus ear rot and aflatoxin production of corn from Tex6. Phytopathology 90:292-296.

14. Huang, Z., White, D. G., and Payne, G. A. 1997. Corn seed proteins inhibitory to Aspergillus flavus and Aflatoxin biosynthesis. Phytopathology 87:622-627.

15. Huynh, Q. K., Hironaka, C. M., Levine, E. B., Smith, C. E., Borgmeyer, J. R., and Shah, D. M. 1992. Antifungal proteins from plants. J. Biol. Chem. 267:6635-6640.

16. Jach, G., Gornhardt, B., Mundy, J., Logemann, J., Pinsdorf, E., Leah, R., Schell, J., and Maas, C. 1995. Enhanced quantitative resistance against fungal disease by combinatorial expression of different barley antifungal proteins in transgenic tobacco. Plant J. 8:97-109.

17. Ji, C., and Kuc, J. 1996. Antifungal activity of cucumber $\beta-1,3-$ glucanase and chitinase. Physiol. Mol. Plant Pathol. 49:257-265.

18. Ji, C., Norton, R. A., Wicklow, D. T., and Dowd, P. F. 2000. Isoform patterns of chitinase and $\beta$-1,3-glucanase in maturing corn kernels (Zea mays L.) associated with Aspergillus flavus milk stage infection. J. Agric. Food Chem. 48:507-511
19. Laemmli, U. K. 1970. Cleavage of structural proteins during the assembly of the head bacteriophage T4. Nature 227:680-685.

20. Levorson, J., and Chlan, C. A. 1997. Plant chitinase consensus sequences. Plant Mol. Biol. Rep. 15:122-133.

21. Lozovaya, V. V., Waranyuwat, A., and Widholm, J. M. 1998. $\beta-1,3-$ Glucanase and resistance to Aspergillus flavus. Crop Sci. 38:1255-1260.

22. Mauch, F., Mauch-Mani, B., and Boller, T. 1988. Antifungal hydrolases in pea tissue. 2. Inhibition of fungal growth by combinations of chitinase and $\beta$-1,3-glucanase. Plant Physiol. 88:936-942.

23. Metzger, G. L., Frundt, C., Vogeli-Lange, R., and Meins, F. J. 1995. Class I $\beta$-1,3-glucanase in the endosperm of tobacco during germination. Plant Physiol. 109:751-759.

24. Nichols, T. E. J. 1983. Economic impact of aflatoxin in corn. Pages 6771 in: Aflatoxin and Aspergillus flavus in Corn. U. L. Diener, R. L. Asquith, and J. W. Dickens, eds. South. Coop. Ser. Bull. 279.

25. Nielsen, K., Payne, G. A., and Boston, R. S. 2001. Maize ribosomeinactivating protein inhibits normal development of Aspergillus nidulans and Aspergillus flavus. Mol. Plant-Microbe Interact. 14:164-172.

26. Nielson, K. K., Bojsen, K., Roepstorff, P., and Mikkelsen, J. D. 1994. A hydroxyproline-containing class IV chitinase of sugar beet is glycosylated with xylose. Plant Mol. Biol. 25:241-257.

27. Payne, G. A. 1992. Aflatoxin in maize. Crit. Rev. Plant Sci. 10:423-440.

28. Russin, J. S., Guo, B. Z., Tugajika, R. L., Brown, R. L., Cleveland, T. E., and Widstrom, N. W. 1997. Comparison of kernel wax from corn genotypes resistant or susceptible to Aspergillus flavus. Phytopathology 87:529-533.

29. Schickler, H., and Chet, I. 1997. Heterologous chitinase gene expression to improve plant defense against phytopathogenic fungi. J. Ind. Microbiol. Biotechnol. 19:196-201.

30. Scott, G. E., and Zummo, N. 1988. Sources of resistance in maize to kernel infection by Aspergillus flavus in the field. Crop Sci. 28:504-507.

31. Seetharaman, K., Whitehead, E., Keller, N. P., Waniska, R. D., and Rooney, L. W. 1997. In vitro activity of sorghum seed antifungal proteins against grain mold pathogens. J. Agric. Food Chem. 45:3666-3671.

32. Squire, R. A. 1989. Ranking animal carcinogens: A proposed regulatory approach. Science 214:887-891.

33. Widstrom, N. W. 1996. The aflatoxin problem with corn grain. Adv. Agron. 56:219-280.

34. Windham, G. L., and Williams, W. P. 1998. Aspergillus flavus infection and aflatoxin accumulation in resistant and susceptible maize hybrids. Plant Dis. 82:281-284.

35. Windham, G. L., and Williams, W. P. 2002. Evaluation of corn inbreds and advanced breeding lines for resistance to aflatoxin contamination in the field. Plant Dis. 86:232-234.

36. Wogan, G. N., Paglialunga, S., and Newburn, P. M. 1974. Carcinogenic effects of low dietary levels of aflatoxin B1 in rats. Food Cosmet. Toxicol. 12:681-685.

37. Wu, S., Kriz, A. L., and Widholm, J. M. 1994. Molecular analysis of two cDNA clones encoding acidic class I chitinase in maize. Plant Physiol. 105:1097-1105.

38. Zhang, Y. M., Kang, S., and Magari, R. 1997. Genetics of resistance to kernel infection by Aspergillus flavus in maize. Plant Breed. 116: 146-152. 